\title{
Paresia recurrente de sexto nervio craneano asociado a hipoplasia de sexto nervio
}

\author{
Cristian Marcelo Salgado ${ }^{1 *}$, Juan Pablo Cruz ${ }^{1}$, Alvaro Esteban Morgado Ahumada ${ }^{1}$
}

Resumen: La paresia de sexto nervio craneano recurrente es una entidad ampliamente conocida en la población pediátrica que ha sido asociado a múltiples etiologías, siendo las más frecuentes las infecciones virales o postinmunizaciones. A continuación, exponemos el caso de una niña de 5 años que presenta 2 episodios de déficit de abducción del ojo izquierdo debido a paresia de sexto nervio craneano, que se resolvieron espontáneamente. El estudio con resonancia magnética reveló hipoplasia del sexto nervio craneano izquierdo.

Palabras clave: Paresia recurrente de sexto nervio craneano; hipoplasia de sexto nervio craneano; infección viral; canal de Dorello

Abstract: Recurrent sixth nerve palsy is a well-known entity in pediatric population associated to multiple causes, most frequently viral infection or immunization. We report a case of a 5 years old girl who presents two episodes of left abduction deficit due to sixth nerve palsy that partially resolved spontaneously. A magnetic resonance imaging study revealed a hypoplastic left sixth nerve.

Keywords: Recurrent sixth cranial nerve palsy; sixth cranial nerve hypoplasia; viral infection; Dorello's canal

Fecha de envío: 10 de julio de 2016 - Fecha de aceptación: 9 de marzo de 2017

\section{Introducción}

El núcleo del nervio abducens se ubica lateral a la línea media en el área dorsal del tercio inferior del puente encefálico, anterior al piso del cuarto ventrículo, formando el colículo facial en conjunto con el genu interno del nervio facial. Después de un trayecto recto anterior intrapontino, abandona el tronco encefálico en la unión pontomedular hacia la cisterna prepontina. Desde aquí atraviesa esta cisterna subaracnoidea y recorre verticalmente por el aspecto posterior del clivus penetrando la duramadre. Posteriormente atraviesa el canal de Dorello, un surco óseo cubierto por un engrosamiento focal del ligamento esfenopetroso, antes de entrar al seno cavernoso, donde se ubica medial a la arteria carótida interna $(\mathrm{ACl})$. Finalmente, el sexto nervio craneano entra a la órbita a través de la fisura orbitaria superior para inervar el músculo recto lateral (Brodsky, 2010).

La paresia de sexto nervio craneano en niños puede presentarse con un giro de cabeza compensatorio hacia el lado afectado y/o con una endotropia que usualmente es mayor para lejos. Existen múltiples etiologías de paresia de sexto nervio. Las principales causas son neoplasias del sistema nervioso central, hipertensión endocraneana, trauma, congénito, inflamatorio e idiopático (Gömez-Gosálvez et al., 2001; Martonyi, 1990).
La paresia de sexto nervio craneano recurrente benigna (PSNRB) es una entidad bien conocida en que ocurren múltiples episodios de paresia de sexto nervio con resolución parcial o total entre cada evento (Werner et al., 1983). Las etiologías propuestas incluyen infecciones virales o inmunizaciones con algunas vacunas antivirales (sarampión, paperas, rubeola) (Werner et al., 1983) o vacuna DPT (difteria pertussis y tétanos) (Boger et al., 1984). Otras etiologías podrían incluir compresión neurovascular por una arteria aberrante y migraña (Brodsky, 2010).

A continuación, reportamos el caso de una niña con episodios recurrentes de paresia de sexto nervio craneano izquierdo asociado a hipoplasia del nervio abducens izquierdo.

\section{Reporte de caso}

Una niña de 5 años fue hospitalizada electivamente para estudio por un segundo episodio de paresia de sexto nervio izquierdo. Sus padres refieren que el primer episodio se manifestó 20 meses previos con diplopía horizontal asociado a endotropia izquierda y déficit ipsilateral de abducción. En ese momento ella fue evaluada en otra institución siendo diagnosticada con una paresia de sexto nervio craneano izquierdo. Cinco meses después la paresia mejoró espontáneamente, pero persistió con endotropia residual,

(1) Departamento de Oftalmología, Escuela de Medicina, Pontificia Universidad Católica de Chile

*Autor de correspondencia: csalgado@med.puc.cl 


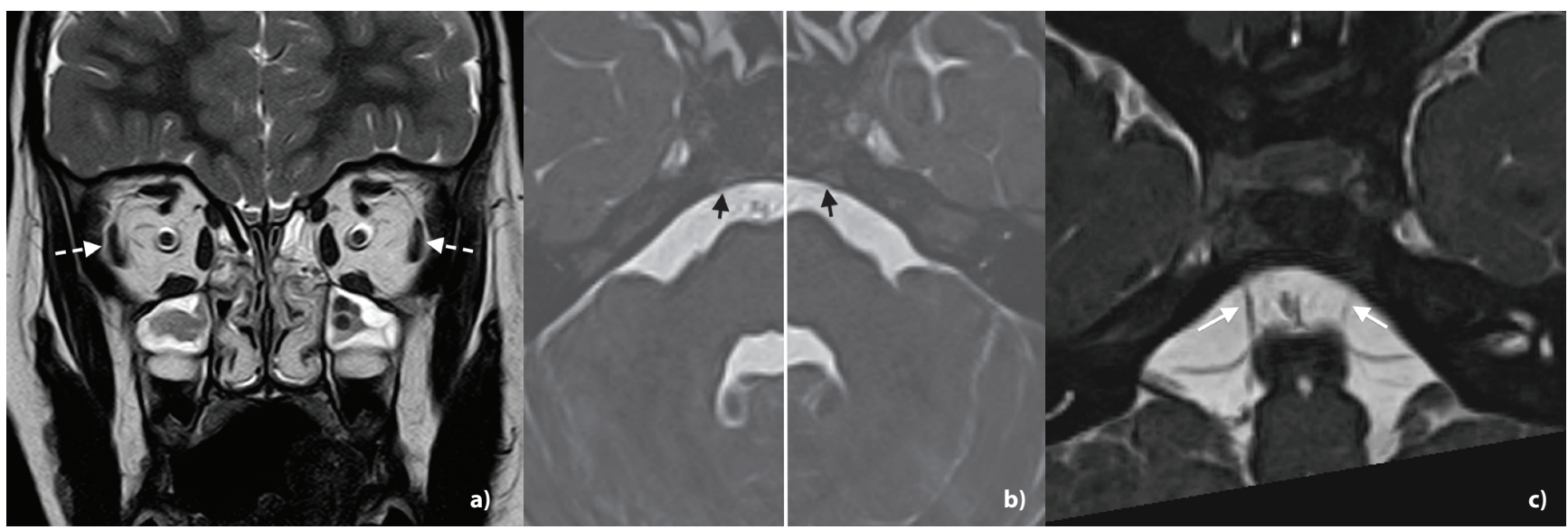

Figura 1: RNM secuencias formato oblicuo multiplanar (grosor $2.5 \mathrm{~mm}$, proyección de intensidad mínima) (a) y axial (b) T2W 3D balanced fast field echo (B-FFE), (c) coronal T2W fast spin-echo. Se aprecia marcada atrofia del segmento cisternal del sexto nervio craneano izquierdo (flechas), con un defecto dural menor del ligamento esfenopetroso (flechas negras), que sirve como un marcador indirecto de la hipoplasia del canal de Dorello. Las imágenes coronales a través de las órbitas muestran músculos rectos laterales normales y simétricos (flechas discontinuas), sin signos de atrofia por denervación en el lado izquierdo.

requiriendo cirugía de estrabismo (retroceso de rectos medios de $5.0 \mathrm{~mm}$ y resección de recto lateral de $7.0 \mathrm{~mm}$ ) en su ojo izquierdo. Posterior a la cirugía la niña evolucionó satisfactoriamente con solo una exotropia intermitente de 10 dioptrías prismáticas.

Cuatro días previos a la hospitalización actual la paciente presenta otro episodio similar (diplopía aguda asociado a endotropia izquierda y déficit ipsilateral de abducción). No hubo presencia de cefalea, compromiso de conciencia, anormalidades auditivas o signos neurológicos focales.

La niña fue tratada de una neumonía viral 2 semanas antes. No presentaba ningún otro antecedente médico de importancia. Solo se reportó uso de lentes para hipermetropía y astigmatismo. No había historia personal o familiar de estrabismo u otras enfermedades neurológicas.

La evaluación oftalmológica mostró agudeza visual de 20/20 en ambos ojos. La estereopsis era de 6/9. La paciente presentaba un pequeño giro de cabeza a izquierda. El cover test mostró una endotropia izquierda de 10 dioptrías prismáticas para cerca y para lejos. La evaluación de la motilidad revela un déficit de abducción de $80 \%$ en su ojo izquierdo. El examen pupilar, neurológico, la evaluación externa y el fondo de ojo fueron normales. No se apreciaba retracción ocular en ninguna posición de mirada, tampoco downshoot ni upshoot. No presentaba el signo de Cogan lid twitch, ptosis, fatigabilidad del músculo elevador del párpado o debilidad del músculo orbicular.
Se realizó una evaluación hematológica general sin hallazgos anormales. Se solicitó una evaluación por neurología sin otros hallazgos clínicos relevantes. Se realizó el test de edrofonio con resultado negativo. Se realizó una resonancia nuclear magnética incluyendo fase $\mathrm{T} 2 \mathrm{~W}$ steady state $3 \mathrm{D}$ con secuencia de gradiente (Phillips Achieva, 1.5T,T2 B-FFE; TE: 3.5ms, TR: 7.1 ms, 50 flip-angle, $0.5 \mathrm{~mm}$ de grosor, sin espacio, matriz $256 \times 256$ ) mostrando un adelgazamiento difuso de la porción cisternal del nervio abducens, sin aumentos anormales de señal (figura 1). No se apreciaron señales anormales pontinas ni lesiones de la base de cráneo. El músculo recto lateral izquierdo mostró grosor y señal normal, sin adelgazamiento ni signos de atrofia por denervación. Los otros músculos extraoculares se apreciaban normales en longitud y grosor.

\section{Discusión}

Han sido reportados en la literatura múltiples casos de PSNRB posvirales o postinmunización con vacunas principalmente en mujeres jóvenes, más frecuentemente afectando el lado izquierdo, siendo raro en adultos (Brodsky, 2010; Werner et al., 1983). Los casos descritos muestran un inicio agudo y recuperación espontánea luego de un periodo de tiempo variable que oscila entre 1 a 6 meses (Werner et al., 1983). Sin embargo, en algunas ocasiones luego de varios episodios recurrentes algún grado de endotropia puede persistir y puede ser necesaria resolución quirúrgica (Brodsky, 2010).

Sandvand et al (2008) reportaron el caso de un hombre de 38 años que presentó 11 episodios de paresia de sexto nervio craneano sin ningún hallazgo que pudiese explicar estos episodios recurrentes. 
Luego de un estudio completó con exámenes de laboratorio e imagenológicos, la angio-RNM reveló un contacto neurovascular patológico entre el nervio abducens y la arteria cerebelar inferoanterior (Sandvand et al., 2008).

Blumenthal et al (1997) reportaron el caso de un paciente de 59 años con 7 episodios de paresia de VI nervio craneano. Al igual que antes, se realizó una evaluación serológica y neurológica sin etiología aparente, pero la evaluación con TAC mostró dolicoestasia del segmento cavernoso de la $\mathrm{ACl}$ y un aneurisma fusiforme de la $\mathrm{ACl}$ supraclinoidea (Blumenthal et al., 1997).

La hipoplasia del nervio abducens es un hallazgo infrecuente que ha sido reportado en múltiples enfermedades como el síndrome de retracción de Duane, la fibrosis congénita de los músculos extraoculares (FCMEO) y el síndrome de Möebius. Sin embargo, esta anormalidad no ha sido descrita en la PSNRB.

La ausencia o adelgazamiento del nervio abducens es una anormalidad comúnmente reportada en el síndrome de retracción de Duane tipo I y III en el lado afectado (Parsa et al., 1998; Ozkurt et al., 2003). También ha sido reportado en el síndrome de Duane tipo II, asociado con un adelgazamiento o inervación anómala del tercer nervio craneano (Denis et al., 2008). Sin embargo, esta anormalidad no ha sido asociada a una disminución del tamaño del músculo recto lateral en la evaluación con RNM, a diferencia de la marcada atrofia que se presenta en la paresia crónica de sexto nervio craneano (Demer et al., 2006).

Otra enfermedad asociada a la hipoplasia del nervio abducens es la FCMEO. Kim \& Hwang (2005) reportó 2 casos de pacientes con FCMEO quienes presentaron hipoplasia bilateral de los sextos nervios craneanos (Kim \& Hwang, 2005). Estos pacientes además mostraron el síndrome de divergencia sinergística. Los hallazgos en RNM descritos en pacientes con FCMEO son hipoplasia severa de tercer nervio craneano, hipoplasia moderada de sexto nervio craneano e hipoplasia de los músculos extraoculares, particularmente severo para los músculos recto superior y elevador del párpado (Demer et al., 2006).

Hemos descrito el caso de una niña de 5 años que presentó PSNRB e hipoplasia de sexto nervio craneano ipsilateral. Solo hemos encontrado 1 caso reportado por Chua et al. (2011) de un lactante de 9 meses que presenta un caso similar a nuestra paciente, con 1 episodio de paresia de sexto nervio craneano asociado a hipoplasia del mismo (Chua et al., 2011).

En el caso reportado por Chua et al. (2011), se describió la presencia de hipoplasia del canal de Dorello en la RNM en secuencia T2W de alta resolución 3D con secuencia de pulso. En nuestro paciente, en un análisis posterior de la RNM, también reveló un estrechamiento del canal de Dorello en el lado afectado. El significado de este hallazgo es incierto. Es bien sabido que el tamaño de los surcos y canales del cráneo depende del desarrollo de su contenido. Por lo tanto, no es claro si la hipoplasia del canal de Dorello es una consecuencia de la hipoplasia del sexto nervio craneano, o la causa de esta como fue postulado por Chua et al (2011).

Con la información actual no podemos establecer fehacientemente una relación causa efecto de la hipoplasia del canal de Dorello y la hipoplasia de sexto nervio craneano, pero probablemente existe alguna asociación entre ambos hallazgos. Por otro lado, podría ser de utilidad evaluar la presencia de microtropia asociado a este cuadro, sin embargo, dada la presencia de un estrabismo residual al momento del examen invalida el test de 4DP y podría estar afectando la estereopsis, test que nos podrían orientar a este diagnóstico. También sería interesante complementar el estudio con evaluación electrofisiológica de los músculos extraoculares una vez resuelto el cuadro agudo con el fin de establecer si hay un grado de compromiso funcional del músculo recto lateral pese a apreciarse anatómicamente normal.

A nuestro saber, este correspondería al segundo caso reportado de un paciente que presenta PSNRB e hipoplasia de sexto nervio craneano y el canal de Dorello.

Conflictos de interés: Los autores declaran no tener conflictos de interés que establecer.

\section{Referencias}

Blumenthal EZ, Gomori JM, Dotan S. (1997). Recurrent abducens nerve palsy caused by dolichoectasia of the cavernous internal carotid artery. American journal of ophthalmology. 124 (2):255-7.

Boger WP III, Puliafito CA, Magoon H, et al. (1984). Recurrent isolated sixth nerve palsy in children. Annals of ophthalmology. 16 (237-238): 240-244.

Brodsky M. Pediatric Neuro-Ophthalmology. (2010). Second edition. New York: Springer.

Chua C, Cooper LL, Wei XC, Ruddell S. (2011). Recurrent sixth nerve palsy associated with a hypoplastic Dorello's canal. Journal of AAPOS. 15 (4):392-4.

Demer JL, Ortube MC, Engle EC, Thacker N. (2006). High-resolution magnetic resonance imaging demonstrates abnormalities of motor nerves and extraocular muscles in patients with neuropathic strabismus. Journal of AAPOS. 10 (2):135-42. 


\section{Salgado et al.}

Denis D, Dauletbekov D, Girard N. (2008). Duane retraction syndrome: Type II with severe abducens nerve hypoplasia on magnetic resonance imaging. Journal of AAPOS. 12 (1):91-3.

Gömez-Gosálvez F, Sala AG, Rubio A. (2001). Acquired oculomotor paralysis in the adolescent. Revista de neurología. 32:241-244.

Kim JH, Hwang JM. (2005). Hypoplastic oculomotor nerve and absent abducens nerve in congenital fibrosis syndrome and synergistic divergence with magnetic resonance imaging. Ophthalmology. 112 (4):728-32.

Martonyi EJ (1990). Pediatric sixth nerve palsy: case reviews and management guidelines. The American orthoptic journal. 40:24-31.
Ozkurt H, Basak M, Oral Y, Ozkurt Y. (2003). Magnetic resonance imaging in Duane's retraction syndrome. Journal of pediatric ophthalmology and strabismus. 40:19-22.

Parsa C, Grant E, Dillon W, duLac S, Hoyt W. (1998). Absence of the abducens nerve in Duane syndrome verified by magnetic resonance imaging. American journal of ophthalmology. 125:400-1.

Sandvand KA, Ringstad G, Kerty E. (2008). Periodic abducens nerve palsy in adults caused by neurovascular compression. Journal of neurology, neurosurgery, and psychiatry. 79 (1):100-2.

Werner DB, Savino PJ, Schatz NJ. (1983). Benign recurrent sixth nerve palsy in childhood, secondary to immunization or viral illness. Archives of ophthalmology. 101:607-608. 